\title{
FEMALE CROSS-DRESSING IN CHINESE LITERATURE CLASSICS AND THEIR ENGLISH VERSIONS
}

\begin{abstract}
Cross-dressing, as a cultural practice, suggests gender ambiguity and allows freedom of self expression. Yet, it may also serve to reaffirm ideological stereotypes and the binary distinctions between male and female, masculine and feminine, homosexual and heterosexual. To explore the nature and function of cross-dressing in Chinese and Western cultures, this paper analyzes the portrayals of cross-dressing heroines in two Chinese stories: 《蘭辭》 The Ballad of Mulan (500-600 A.D.), and 《梁山岶與祝英台》The Butterfly Lovers (850-880 A.D.). Distorted representations in the English translated texts are also explored..
\end{abstract}

KEY WORDS: Female cross-dressing, gender role, parody, performativity, patriarchal hegemony.

\section{Introduction}

Cross-dressing, or the act of adopting the role and many of the customs of the opposite gender, "implies different things in different cultures and has been viewed historically in widely varying ways" (Bullough and Bullough 3). For centuries, terms such as "gynemimesis, andromimesis, gender dysphoria, female or male impersonation, transgenderist, femmiphile, androphile, femme mimic, fetishist, crossing, transsexual," (Bullough and Bullough 3) etc. have been introduced to describe cross-dressing. The wide range of terms indicates that people have come across and perceived the idea of cross-dressing in various ways. For

* The Open University of Hong Kong, 30 Shepherd Street, Ho Man Tin, Kowloon, Hong Kong. E-mail: atso@ouhk.edu.hk 
instance, early physicians and psychiatrists in the West had the inclination to medicalize cross-dressing and queer identities as an illness or a mental problem. Yet, for radical feminists such as Judith Butler, drag and cross-dressing can be a witty parody of the imitative structure of gender. In Chinese literature, cross-dressing is sometimes portrayed as "unsocialized pleasure" (Dyer 7), namely the kind of unruly delight that breaks free from the discipline of formally well-behaved narrativity and staid, coherent points of view. At other times, cross-dressing is nothing more than a plot device. To find out the different implications of cross-dressing, this paper looks into the representations of female cross-dressing in two well-known Chinese stories: The Ballad of Mulan (500-600 A.D.) compiled in Guo Maoqian's Music Bureau Collection (twelfth century), and The Butterfly Lovers (850-880 A.D.).

The paper will also compare the representations of crossdressing in the Chinese texts with those in their English adaptations. The variations found in the English texts will be examined and analyzed on the story level (what is being toldincidents, characters, etc.), as well as on the discourse level (how it is told) (O'Sullivan 81). The two English texts to be looked at are Charlie Chin's China's Bravest Girl: The Legend of Hua Mu Lan (1993) and The Butterfly Lovers (1995), retold by Lee Geok Lan. The variations in the representations of cross-dressing between the Chinese and English texts will shed light on the different attitudes and ideological assumptions about gender.

In the following, I will first recapture Butler's ideas of gender performativity, drag and parody, which will later on be employed to discuss the various representations of cross-dressing in the chosen texts.

\section{What is Gender Performativity?}

Gender Performativity is a term coined by Judith Butler, the poststructuralist feminist. Drawing on the claim made in Nietzsche's On the Genealogy of Morals, that "there is no "being" behind doing, acting, becoming; "the doer" is merely a fiction imposed on the doing-the doing itself is everything" (29), in the first chapter of Gender Trouble (1999), Butler introduces the idea of performativity: "[ $\mathrm{t}]$ here is no gender identity behind the expressions of gender; that identity is performatively constituted 
by the very "expressions" that are said to be its results" (33). She argues that gender is merely a construction regardless of any ontological truth. "[T]here is neither an 'essence' that gender expresses or externalizes nor an objective ideal to which gender aspires" (Butler, "Performative Acts and Gender Constitution: An Essay in Phenomenology and Feminist Theory" 273). For Butler, gender is not genetically coded. It does not happen once and for all when we are born. Instead, it is "a sequence of repeated acts that harden into the appearance of something that's been there all along" (Salih 66). In other words, femininity, masculinity and heterosexual identities are all everyday performativity. They are constructed, represented, repeated and, in turn, reinforced as if they are ordained by Nature. They are fabricated at the moment when they are performed. In chapter three of Gender Trouble, Butler continues to develop her argument:

If the inner truth of gender is a fabrication and if a true gender is a fantasy instituted and inscribed on the surface of bodies, then it seems that genders can be neither true nor false, but are only produced as the true effects of a discourse of primary and stable identity (174).

In this light, all gender is a form of parody. It is a "corporeal style" (Gender Trouble 177), a "stylized repetition of acts" (Gender Trouble 179), and "a copy of copy" (Salih 66). However, such gender parody or performativity should not be interpreted as something that can be put on and off at will, like a costume or role. As Butler declares in Bodies That Matter "performativity must be understood not as a singular or deliberate "act," but, rather, as the reiterative and citational practice by which discourse produces the effects that it names" (1).

\section{Drag and Parody}

While the majority in society is unwittingly engaged in this sort of ordinary, everyday gender practice, drag performances are subversive. As Butler explains, "in imitating gender, drag implicitly reveals the imitative structure of gender itself-as well as its contingency" (Gender Trouble 175). By citing 'the feminine' through a range of signifiers such as mascaraed eyelashes, prominent breasts, movements of hips, which have no point of origin in any female body, drag acts disrupt the assumption of heterosexuality (Brook 114). They allow "the possibilities of 
denaturalizing, proliferating and unfixing identities in order to reveal the constructed nature of heterosexuality" (67).

That said, it is important to note that not all forms of drag are subversive. In fact, there are drag performances which serve to reinforce and confirm the existing distinctions between male and female, masculine and feminine, gay and straight. Dustin Hoffman's performance in Tootsie (1982), for instance, demonstrates how certain denaturalizations of the heterosexual norm actually enforce heterosexual hegemony (Body That Matters 231). Such entertainment, according to Butler, is "a ritualistic release for a heterosexual economy that must constantly police its own boundaries against the invasion of queerness" (Body That Matters 126).

\section{Cross-dressing of Mulan, the Chinese Woman Warrior}

To explore whether cross-dressing in Chinese literature classics serves to destabilize or reaffirm heterosexual hegemony, I will first examine Mulan, the female cross-dressing character in 《蘭辭》, The Ballad of Mulan (500-600 A.D.).

\section{"The Ballad of Mulan," a Glorious Break from of Patriarchal Constraints}

Mulan, or Hua Mulan, is a young Chinese heroine who disguises herself as a male warrior, joins the army and goes off to war in her old father's stead. Like most folklore, the time setting of the story is uncertain, but the earliest text that recounts the legend of Mulan can be dated as far back as to the fifth century C.E., when China was dominated by the Wei Tartars (Wang, Images of Women in Chinese Thought and Culture 250). The poem, known as The Ballad of Mulan, was first written in the Musical Records of Old and New, but the popular version well-known to most Chinese is from Guo Maoqian's Music Bureau Collection (twelfth century).

What is remarkable about The Ballad of Mulan is that it is one of the earliest texts that challenge the oppressive patriarchal constraints on Chinese women. The Confucian doctrine requires women to stay home and perform the conventional female duties and virtues. 'Virtuous women' are expected to follow the rituals of 
three obediences, which mean that before marriage, a woman should obey her father; after marriage, she is to obey her husband; finally, after the death of her husband, she should obey her son, if she has any. In other words, "a girl is . . trained to be respectful and submissive from birth" (Xiao 13). Men will decide what is good and appropriate for them. A decent Chinese woman should not make any decisions for herself at any point of her life. Besides the three obediences, women must also make sure that they possess four womanly virtues so as to become a truly "virtuous woman." According to Ban Zhao's Nujie [Precepts for women] (compiled in Hou Han shu, 1965), the four virtues are (1) chastity and fidelity, (2) womanly words, (3) womanly bearing; and (4) womanly work. Simply put, a good woman is supposed to behave modestly, speak softly, dress up prettily and work (sew and weave) diligently in order to please and honour her husband and family.

By viewing The Ballad of Mulan, we can argue that Mulan is not the kind of virtuous woman that the traditional Chinese society would expect. Instead, in the name of filial piety to her father, Mulan sets the three obediences aside-she makes up her mind to fight in place of her father:

\footnotetext{
昨夜見鄆占 But last night I read the battle-roll;

可汗大點兵 The Kehan has ordered a great levy of men.

軍書十二卷 The battle-roll was written in twelve books,

卷卷有爺名。And in each book stood my father's name.

阿㿽無大兒 My father's sons are not grown men,

木菓無長兄 And of all my brothers, none is older than I.

願為市鞍馬 Oh let me go to the market to buy saddle and horse,

從此替爺徵 And ride with the soldiers to take my father's place.
}

(English translation by Waley 251)

The narrative indicates that Mulan does not obey her father. Rather, she has the full subjectivity to make the decision all on her own. From the text, it seems that regarding the military announcement, neither have the people concerned shown any expectations from Mulan, nor has Mulan sought advice and permission from anybody. What happens is that she tells her father she wants to fight in place of him, and all her father can do is just to believe in Mulan, keep quiet, and let her go off to war for him. Also, whether it is before, during or after the military service, not once has Mulan followed any orders from a male. Her husband and son are either not mentioned, or they simply do not 
exist in the ballad. Mulan is not under the constraint of the three obediences.

Apart from the three obediences, Mulan has also subverted some of the womanly virtues. At the beginning of the ballad, it is said that like other women, Mulan weaves and performs womanly work, "Mulan sits at the door and weaves" (Translated by Waley 251). Yet, as she puts on her armour, she hides her gender identity and gains power from her cross-dressing. Under the disguise, she walks out of the domestic sphere and leaves the womanly work behind. She trespasses into the sphere of the opposite sex, and gets promoted to the public sphere. Similarly, when Mulan joins the all-male army, she sets herself free from her womanly bearing. The cross-dressing is so successful that, for twelve years, not a single man discovers her gender identity. Thus, when Mulan finally dresses as a lady after the war is over, her fellow battle companions are all astounded, "Her messmates were startled out of their wits" (Translated by Waley 254). Intriguingly, there is a hint of unruly delight towards the end of the ballad:

\begin{tabular}{|c|c|}
\hline 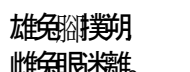 & For the male hare has a lilting, lolloping gait, \\
\hline 雙免䧛也走 & But set them both scampering side by side, \\
\hline
\end{tabular}

(English translation by Waley 254)

Regarding the ending of Mulan's story, Li claims that "Mulan's crossing of gender lines is only provisional" (86), because at the end of the story, "Mulan is decorated by the emperor, returns home, removes her male garment, is reunited with her family" (86). Indeed, as $\mathrm{Li}$ points out, the story does end with the unmasking of the cross-dressing. The division of gender spheres is reinstated and reaffirmed on the narrative level. In fact, considering the cultural setting when the ballad was written, it is not surprising that the story ends with Mulan returning to the domestic sphere after the war, as the narrative recounts. On the story level, however, Mulan, the cross-dresser is not punished for deceiving her battle companions with her disguise. Also, on the discourse level, the last four lines of the ballad (as cited above) reflect a subtly subversive attitude that challenges the Confucian gender system-the gender transgression of Mulan is not taken as a taboo, nor is it portrayed as sinful, immoral, or disgusting. To a certain extent, the disguise is represented and perceived as 
a delightful temporary escape from the oppressive patriarchal hegemony. The playful tone is especially strong in the last line, "And who so wise could tell you "This is he?" (Translated by Waley 254).

Although the narrative does not imply that gender identity can be fabricated, the rhetoric style helps open up an alternative way of seeing: a buck or a doe, male or female, there is a possibility that both might look and behave the same, in spite of their true sex. How do we distinguish the two?

\section{Chin's Version: Mulan as a Dutiful Daughter and Wife}

Because of the popularity of the legend of Mulan, there are numerous translations and adaptations made for English readers too. Charlie Chin's China's Bravest Girls: the Legend of Hua Mu Lan (1993), an English picture book, is one typical example among the many English versions. A great deal of difference can be found throughout the adaptation. First of all, on the discourse level, the 'doe and buck' metaphor that describes gender confusion is replaced. The narrative compares Mulan to a pearl hiding in an oyster:

The ocean hides the oyster.

The oyster hides a pearl.

Bright armor and heavy helmet

Hid China's bravest girl (Chin 24).

In the Chinese language, the first part of the word 'pearl' (珍珠 zhen-zhu) is pronounced the same as the word 'real' (真 zhen). Because of the sameness in pronunciation, a pearl is commonly used as a metaphor for the real, the authentic or the essence. One well-known Chinese idiom, 'a fish-eye mixed in pearls' (魚目混朱 yu mu hun zhu) also employs the metaphor, in which pearls represent the real and the precious, whereas a fish-eye refers to a fake pearl, or something that is just a copy of the real. Thus, comparing Mulan to a pearl is a subtle way of making the point that the true gender is out there. It can be hidden but it can never be fabricated. Discarding the metaphor of "a doe and a buck" and replacing it with the metaphor of "a hidden pearl in an oyster" is, therefore, an act to get rid of the sense of queerness and unruly delight submerged in the original version. 
In addition to the change of metaphor, Chin also puts an emphasis on the female's role, which every woman should play. In the original text, the story ends with Mulan choosing to return to her former way of life. For this, not much explanation is given in the ballad-there could be thousands of reasons why Mulan wants to go home. It could be that she misses her hometown, or that she is bored with life in the military, etc. The reader is given room for free interpretation. Yet, in Chin's adaptation, the reason that Mulan returns home is clearly stated:

There's nothing that I desire,

neither wealth nor minister's post.

My duty is to my father.

In old age, he needs me most (18, my emphasis).

"My duty is to my father" is obviously an indication of Mulan's devotion towards the 'Three Obediences'. Mulan the heroine, still sees herself as the subordinate-she is her father's dutiful daughter. The traditional gender position is further reinstated as the story unfolds. Towards the end of Chin's version, Mulan gets married and becomes her comrade's wife. It is said that Mulan dresses herself up femininely "for the wedding in her husband's hall" (28). This is yet another hint of Mulan fulfilling the second obedience-as her husband's faithful wife, Mulan puts on what pleases her husband's eyes. With the "Three Obediences" in mind, Mulan can by no means be free from the female role of being a daughter, a wife and a mother. The playful tone suggesting the unruly delight of cross-dressing is dismissed.

\section{Cross-dressing of Yingtai, the Female Scholar in The Butterfly Lovers}

Another female cross-dresser well-known to all Chinese readers is Zhu Yingtai in the Chinese love story, The Butterfly Lovers (also known as Liang Shanbo yu Zhu Yingtai), which is often regarded as the Chinese equivalent to Romeo and Juliet. The earliest narrative of the legend of The Butterfly Lovers was found to be in the late Tang Dynasty, recorded in Zhang Du's Records of the Xuan Hall (850-880 A.D.). In the story, a young woman called Zhu Yingtai from a noble family disguises herself as a young male scholar and studies in a renowned school in Hangzhou. During 
her studies, Yingtai meets Liang Shanbo. Studying at the same school and sleeping on the same bed for three years, Yingtai secretly falls in love with Shanbo, but her disguise remains undiscovered after she finishes her studies. Before parting with Shanbo, Yingtai manages to remind Shanbo to pay her a visit. Unfortunately, when Shanbo visits Yingtai and finally realizes that she is a woman, Yingtai's family has already decided that Yingtai should marry Ma Wencai, a young gentleman from a rich family. In despair, Shanbo falls seriously ill and dies of a broken heart. On Yingtai and Ma Wencai's wedding day, there is a thunderstorm. The disheartened Yingtai insists on going to Shanbo's tomb though the wedding procession is not supposed to go past it. When she reaches the place where Shanbo is buried, the tomb suddenly opens up. And Yingtai throws herself into the tomb to join her beloved Shanbo. Since the tragic death of the lovers, two butterflies are often seen flying around Shanbo's tomb. People believe that they are the spirits of Yingtai and Shanbo. The young lovers are therefore called "butterfly lovers."

Yingtai's male disguise, compared with Mulan's, is very different. In Chinese culture, besides the binary opposition of "yin" and "yang," which refers to female and male respectively, there is also the "wen-wu" binary in the idea of maleness. According to Louie, as stated in the Great Chinese Dictionary, the core meaning of "wen" centres around "literary and other cultural attainment" (10), whereas that of "wu" centres around "martial, military, force and power" (10). While "wu" is similar to the contemporary Western idea of maleness, "wen" refers to "soft masculinity" (Wang, "Mr. Butterfly in Defunct Capital" 41). A man of "wen" (or "caizi," a talented male scholar) is usually not a tough, muscular warrior, but an educated, handsome male with "sophisticated cultural tastes in art and literature" (Wang, "Mr Butterfly in Defunct Capital" 41). Like "ladies," "caizi" almost always have "fair skin, elegant features and delicate physiques, as well as tender voices and romantic hearts" (Wang, "Mr. Butterfly in Defunct Capital" 42). The delicate features of caizi is a reflection of his cultural cultivation and literary talent. In this light, we can imagine that the cross-dressing of Mulan is relatively more challenging, for to become a convincing "wu" hero, Mulan must both look like a man and fight like a man. On the other hand, the disguise of Yingtai is easy. As a "wen" hero (or "caizi"), Yingtai does not need to hide her feminine appearance. Wearing male 
attire, her effeminate look is just what a "caizi" is expected to look like. Such cross-dressing may not create the subversive effect that Butler suggests.

\section{Chinese Version: Yingtai as a Convincing Cross-dresser}

As in a recent Chinese version of Butterfly Lovers tailor-made for young Chinese readers, cross-dressing as a caizi (a talented male scholar) is portrayed to be easy and convenient, despite the fact that the cross-dresser has to put on the disguise for three years, day and night without a break. For instance, in the children's story book, Yingtai's parents do not permit Yingtai to study in a boys' college, unless Yingtai cross-dresses as a boy (source text: 條牛是她汹燍妢男裝 (44) English translation: “the condition is that she [Yingtai] must disguise herself as a male.")

The implication is that the disguise as a "caizi" is easy and convincing. The chance of being unmasked is considered low. Thus, Yingtai's parents are fine with the cross-dressing of their daughter. Also, when Yingtai puts on her male disguise, the narrative remarks that Yingtai's new look is convincing: (source text: 居然也有幾分男了的英韕慨 (44); English translation: “Unexpectedly, [Yingtai] shows some manly, handsome features.")

In addition, it is repeatedly mentioned that as Yingtai's close companion, Shanbo discovers nothing about her real gender identity. On page 45, it is written that “梁山怕為人䁻厚成實.. 他一直沒有察覺有什麼異樣” Translated into English, the sentence means "the honest Shanbo does not notice anything abnormal [about Yingtai]." On page 46, the narrator reminds the readers again that the cross-dressing is successful, “倆人在司一張床二年, 梁山伯還是一點也不知道祝英台原是女兒身.” (English translation: “The two of them sleep on the same bed for three years, but still, Shanbo does not realize that Yingtai is a woman"). No matter how many times Yingtai subtly reveals to Shanbo her real gender and her secret love for him, still Shanbo does not get it. On Yingtai's gender switching, Altenburger remarks:

the story's unfortunate ending with the impossibility of marriage and the reunion in death indicates that Zhu Yingtai's male impersonation caused a lasting rupture in the gender order. Therefore, she cannot seamlessly revert to her "original" gender role anymore ... (181). 
The tragic ending can be viewed as a punishment for the violation of the code of morality. The cross-dressing though is far from the kind of "subversive parody" that Butler mentions. That said, Yingtai's easy disguise nonetheless proposes a possibility that gender identity can be "an achieved status" based on "tasks performed" and "the significance of clothing" (Bullough and Bullough 5). Indirectly and subtly, the socio-cultural construction and gender roles are questioned.

\section{English Version: Yingtai as a Cautious, Self-conscious Cross-dresser}

Also written for junior readers, Lee Geok Lan's The Butterfly Lovers (1995) is an English adaptation especially designed for English learners. However, unlike the Chinese version, in Lee's text, Yingtai's disguise is hard. Before Yingtai cross-dresses as a young man and travels to Hangzhou, her father makes her promise to obey three important conditions: firstly, to protect the honour of the Zhu family, the disguise must never be found out. Secondly, as a dutiful daughter, Yingtai must return home immediately should her mother's health turns worse. Finally, and most importantly, to safeguard her chastity, when Yingtai comes home, her father will ask a midwife to "find out if [she is] still as virtuous as an unmarried woman should be" (20). Chained by these constraints and surveillance, limited room is left for the cross-dresser to become spirit-free and playful.

For a couple of times, Yingtai's male impersonation is on the verge of being unmasked. The first time Shanbo notices something different about his friend is when he helps the drunk Yingtai to get into bed: "Shanbo noticed that her [Yingtai's] undershirt had numerous buttons like that of a woman's" (35). Yingtai then explains immediately to Shanbo that wearing a female undershirt is "an act of filiality" (35). Besides the female undershirt, Shanbo also discovers other suspicious features-for instance, he is shocked to find out that Yingtai's earlobes have been pierced. Fortunately, Yingtai is witty enough to provide a good reason just in time, "[a]s I was a child, my mother believed that I would be protected from all bad luck by having both my ears pierced" (47). Interestingly, Shanbo is not the only one who is amazed by the effeminate traits shown by Yingtai and her "page boy," Yin Xin. When Yin Xin asks for a needle and some thread 
from Mrs. Zhou, the wife of the schoolmaster, Mrs. Zhou cries, "But sewing is only for girls!" (38). On hearing Mrs. Zhou's startled exclamation, Yingtai is left with no choice but to tell more lies, "It's good for us boys to learn to sew a few stitches whenever we are far away from home" (38).

Under the constant threat of being unmasked and bringing shame to the Zhu family, Yingtai becomes extremely cautious. For example, despite the hot weather in summer, she wears two layers of clothes to hide her feminine figure. She dares not take off her clothes "for fear that others might notice" (37). Often, she reminds herself that she must watch out for being discovered by Shanbo: "I must be very careful, even though Brother Liang is a true gentleman" (35). Yingtai is also worried that some people might find her disguise inadequate and suspicious. Even a curious smile can arouse her anxiety, "she [Yingtai] suddenly remembered how Mrs. Zhou had smiled at them ... as if she suspected something was not quite right" (39). Under enormous stress, Yingtai can hardly enjoy her cross-dressing. She even goes as far as to warn Ying Xin to be extra careful when talking to people whom she suspects. In sum, Yingtai's cross-dressing in the English version is not as easy as that in the Chinese version. Also, it is not a jolly, unruly delight, as represented in The Ballad of Mulan.

\section{Conclusion}

In Gender Trouble (1999), Butler makes the point that drag performances could be seen as a subversive parody that mocks the existing heterosexual power structures. Yet, looking at how cross-dressing is represented in the selected Chinese texts and their English versions, one will be disappointed. The implications of the cross-dressing motif are rarely subversive. Noticeably, in the English versions, the representations of cross-dressing become more conservative and less 'problematic'. Compared with the Chinese versions, the subversive effect in the English versions of cross-dressing is reduced, if not eliminated.

In the legend of Mulan, temporary transgression of gender borderlines appears when the female protagonist disguises as a male soldier and goes off to war for her old father. In the original Chinese version, The Ballad of Mulan (500-600 A.D.), the female cross-dressing can be viewed as an unruly delight, at most a 
temporary escape from the oppressive patriarchal hegemony. Although the cross-dressing does not last forever, the last lines of the poem put forward a hint of playfulness. They subtly suggest the possibility and plausibility that both male and female can look the same, in spite of their true sex identity. Yet, in Chin's English version, the playful tone is removed. A new ending has been added to the plot-Mulan does not only return to the traditional role of being a daughter, she also becomes her comrade's wife. The gender hierarchy is neatly rendered and reconfirmed.

As for The Butterfly Lover, the female protagonist Yingtai is allowed a temporary space to emancipate herself from the suffocating traditional gender roles. In the Chinese version of The Butterfly Lovers, Yingtai's disguise as a caizi (male scholar) is represented as easy, convenient and convincing. The basic image of the 'wen' masculinity is sufficiently conveyed. Nonetheless, at the end of the story, the temporary usurpation of male power has to end. The deception is punished with an irreversibly tragic ending. Similarly, in the English version of The Butterfly Lovers, the stress on the threat of being unmasked and bringing shame to the family is magnified. Cross-dressing is neither an unruly delight nor a subversive parody.

\section{Works Cited}

Altenburger, Roland. "Is it Clothes that Make the Man? Cross-dressing, Gender, and Sex in Pre-twentieth-century Zhu Yingtai Lore." Asian Folklore Studies, 64.2 (October 2005) 165-205.

Brook, Barbara. Feminist Perspectives on the Body. London and New York: Longman, 1999.

Bullough, Vern L. and Bonnie Bullough. Cross Dressing, Sex and Gender. Philadelphia: University of Pennsylvania Press, 1993.

Butler, Judith. Gender Trouble: Feminism and the Subversion of Identity. New York and London: Routledge, 1999.

-----. Bodies That Matter: On the Discursive Limits of 'Sex'. New York: Routledge, 1993.

-----. "Performative Acts and Gender Constitution: An Essay in Phenomenology and Feminist Theory." Ed. Sue Ellen Case. Performing Feminism: Feminist Critical Theory and Theatre., Baltimore: John Hopkins UP, 1990.

Chin, Charlie. China's Bravest Girl: The Legend of Hua Mu Lan. California: Children's Book Press, 1993.

Dyer, Richard. Only Entertainment. London: Routledge, 1992.

Hou Han shu [The Book of post-Han Dynasty]. Beijing: Zhonghua shuju, 1965.

Lee, Geok Lan. The Butterfly Lovers. Singapore: Federal Publications, 1995. 
Li, Siu Leung. Cross-Dressing in Chinese Opera. Hong Kong: Hong Kong University Press, 2003.

Liang Shanbo yu Zhu Yingtai [In Chinese]. Hong Kong: Outstanding Publication Ltd., 2004.

Louie, Kam. Theorizing Chinese Masculinity: Society and Gender in China. Cambridge, U.K.: Cambridge University Press, 2002.

Nietzsche, Friedrich. On the Genealogy of Morals. Trans. Walter Kaufmann and R.J. Hollingdale. New York: Vintage Books, 1989.

O'Sullivan, Emer. Comparative Children's Literature. London and New York: Routledge, 2005.

Salih, Sara. Judith Butler. London and New York: Routledge, 2002.

Mulan ci [The Ballad of Mulan]. Trans. Arthur Waley. Indianapolis, Cambridge: Hackett Publishing Company, Inc., 1923, 2003.

Tootsie. Dir. Sydney Pollack. Film. Columbia TriStar Home Entertainment, 1982.

Wang, Robin R. Introduction to "The Ballad of Mulan." Ed. Robin R. Wang. Images of Women in Chinese Thought and Culture: Writings from the Pre-Qin Period through the Song Dynasty. Indianapolis, Cambridge: Hackett Publishing Company, Inc., 2003.

Wang, Yiyan. "Mr Butterfly in Defunct Capital: "Soft" Masculinity and (Mis)engendering China." Ed. Kam Louie and Morris Low. Asian Masculinities: The meaning and practice of manhood in China and Japan. London and New York: Routledge Curzon, 2003.

Xiao, Lily Hong Lee. The Virtue of Yin: Studies on Chinese Women. Honolulu: University Hawaii Press, 1994. 